\title{
Advances in chemical product design
}

\section{Zhang, Lei; Fung, Ka Yip; Wibowo, Christianto; Gani, Rafiqul}

\section{Published in:}

Reviews in Chemical Engineering

Link to article, DOI:

10.1515/revce-2016-0067

Publication date:

2018

Document Version

Publisher's PDF, also known as Version of record

Link back to DTU Orbit

Citation (APA):

Zhang, L., Fung, K. Y., Wibowo, C., \& Gani, R. (2018). Advances in chemical product design. Reviews in Chemical Engineering, 34(3), 319-340. https://doi.org/10.1515/revce-2016-0067

\section{General rights}

Copyright and moral rights for the publications made accessible in the public portal are retained by the authors and/or other copyright owners and it is a condition of accessing publications that users recognise and abide by the legal requirements associated with these rights.

- Users may download and print one copy of any publication from the public portal for the purpose of private study or research.

- You may not further distribute the material or use it for any profit-making activity or commercial gain

- You may freely distribute the URL identifying the publication in the public portal

If you believe that this document breaches copyright please contact us providing details, and we will remove access to the work immediately and investigate your claim. 


\section{Lei Zhang, Ka Yip Fung, Christianto Wibowo and Rafiqul Gani* Advances in chemical product design}

DOI 10.1515/revce-2016-0067

Received December 23, 2016; accepted March 30, 2017; previously

published online May 5, 2017

\begin{abstract}
The nature of chemical product design problems is diverse and multidisciplinary. It involves many design issues such as project management, market study, product design, process design, and economic analysis for better organizing the product design project and achieving better products. This article provides an overview of chemical product design with a multidisciplinary hierarchical framework including all the design issues and tasks. Each of the design issues and tasks are introduced and discussed, methods and tools are summarized and compared, challenges and perspectives are presented to help the chemical product design researchers on finding more novel, innovative and sustainable products, by the combined effort from academia and industry to develop a systematic generic framework, and tools including product simulator, process simulator, database manager, modeling tool, and templates for design problems.
\end{abstract}

Keywords: chemical product design; economic analysis; market study; process design; project management.

\section{Introduction}

With an ever-changing global business environment that requires a short time-to-market for products, there is an urgent need in the chemical engineering community to expand the focus from commodity chemicals to chemical-based consumer products and from process design to product and process development. Chemical products are made from other chemicals, which meet

*Corresponding author: Rafiqul Gani, Department of Chemical and Biochemical Engineering, Technical University of Denmark, Lyngby DK-2800, Denmark, e-mail: rag@kt.dtu.dk

Lei Zhang: Department of Chemical and Biomolecular Engineering, The Hong Kong University of Science and Technology, Clear Water Bay, Hong Kong; and Institute of Process Systems Engineering, School of Chemical Engineering, Dalian University of Technology, Dalian 116012, China. http://orcid.org/0000-00027519-2858

Ka Yip Fung: Department of Chemical and Biomolecular Engineering, The Hong Kong University of Science and Technology, Clear Water Bay, Hong Kong

Christianto Wibowo: ClearWaterBay Technology, 4000 Valley Blvd. Suite 100, Pomona, CA 91789, USA specific needs of functionality and utility. More than 70,000 chemical products are used in the modern society, including agrichemicals, ceramics, elastomers, electronic materials, explosives, foods, flavors and fragrances, fuels, industrial gases, inorganic chemicals, metals, oleochemicals, petrochemicals, pharmaceuticals, plastics, and textiles (Seider et al. 2017). Chemical product design determines the structure and composition of a system of single or multiple species that satisfies a set of desired properties and functions. It decides what to make. Chemical process design establishes a practical means to convert raw materials to products with desired properties and functionality via a series of processing steps. It decides how to make the product. In process design, the products are specified, and engineers focus on models of manufacturing process to select among process alternatives the one with the lowest cost. In product design, neither product nor process is specified; engineers focus on models of product properties to select among product alternatives the one with enhanced product properties. Efforts have been made during last two decades to develop methods, tools, software, and databases for product design and development. As product design is multidisciplinary in nature, these studies cover various disciplines such as material science, chemical engineering, industrial engineering, electronic engineering, marketing, and management. This wide spectrum of activities in product design has been captured by the multidisciplinary hierarchical framework (Figure 1) by Cheng et al. (2009) and Seider et al. (2017). The design activities span three phases in time - product conceptualization, detail design and prototyping, and product manufacturing and launch, which can be classified by five job functions - management, sales and marketing, research and design, manufacturing, and finance and economics. These activities can be grouped into various design tasks such as project management, market study, product design, process design, and economic analysis. Many of these design tasks, italicized in Figure 1, are handled by a chemical engineer, sometimes with inputs from personnel from other disciplines, whereas the rest are totally handled by personnel from other disciplines. For example, product specifications cannot be fixed by engineers without the input from the business team working on consumers' preferences, whereas the marketing strategy is primarily developed by marketing experts.

Many product design review articles focus on a specific topic in product design. Gani (2004) reviewed computer-aided molecular design (CAMD) methods for 


\begin{tabular}{|c|c|c|c|}
\hline Job function & $\begin{array}{l}\text { Phase I } \\
\text { Product Conceptualization }\end{array}$ & $\begin{array}{l}\text { Phase II } \\
\text { Detail Design \& } \\
\text { Prototyping }\end{array}$ & $\begin{array}{l}\text { Phase III } \\
\text { Product Manufacturing \& } \\
\text { Launch }\end{array}$ \\
\hline Management & \multicolumn{2}{|l|}{$\begin{array}{l}\text { Project management } \\
\text { - Set product development } \\
\text { objective-time chart } \\
\text { - Secure the necessary human, } \\
\text { financial and physical } \\
\text { resources }\end{array}$} & $\begin{array}{l}\text { - Consider business alliances } \\
\text { - Manage design changes }\end{array}$ \\
\hline \multirow[t]{2}{*}{$\begin{array}{l}\text { Sales and } \\
\text { Marketing }\end{array}$} & $\begin{array}{l}\text { Market study } \\
\text { - Collect consumer preferences } \\
\text { - Identify product attributes } \\
\text { - Study competing products }\end{array}$ & $\begin{array}{l}\text { - Develop marketing plan } \\
\text { - Identify a family of products } \\
\text { - Test marketing }\end{array}$ & $\begin{array}{l}\text { Product launch } \\
\text { - Develop promotional and } \\
\text { launch materials } \\
\text { - Firm up key buyers or sales } \\
\text { channels }\end{array}$ \\
\hline & \multirow{2}{*}{$\begin{array}{l}\text { Product design } \\
\text { - Choose ingredients and base- } \\
\text { case formula } \\
\text { - Identify product structure } \\
\text { - Measure physical and chemical } \\
\text { properties of product } \\
\text { - Specify product technical } \\
\text { requirements }\end{array}$} & $\begin{array}{l}\text { Prototyping } \\
\text { - Fabricate prototype } \\
\text { - Characterization of prototype } \\
\text { - Stability tests } \\
\text { - Performance tests } \\
\text { - Study product safety }\end{array}$ & $\begin{array}{l}\text { - Continue product improvement } \\
\text { - Investigate related products } \\
\text { - Consider development of } \\
\text { technology platform }\end{array}$ \\
\hline $\begin{array}{l}\text { Research } \\
\text { and Design }\end{array}$ & & $\begin{array}{l}\text { Process design } \\
\cdot \text { - Synthesize manufacturing } \\
\text { process }\end{array}$ & - Continue process optimization \\
\hline \multirow[t]{2}{*}{ Manufacturing } & \multirow{2}{*}{$\begin{array}{l}\text { Feasibility study } \\
\text { - Process conceptual design } \\
\text { - Estimate product cost } \\
\text { - Identify sources of raw } \\
\text { materials } \\
\text { - Investigate patent issues } \\
\text { - Study environmental impact }\end{array}$} & $\begin{array}{l}\text { Engineering design } \\
\text { - Perform scale-up studies } \\
\text { - Procure necessary equipment } \\
\text { - Perform engineering design }\end{array}$ & \multirow[t]{2}{*}{$\begin{array}{l}\text { Plant startup } \\
\text { - Obtain regulatory approvals } \\
\text { - Plant startup } \\
\text { - Develop inventory control } \\
\text { scheme }\end{array}$} \\
\hline & & $\begin{array}{l}\text { Economic analysis } \\
\text { - Perform make-buy analysis }\end{array}$ & \\
\hline $\begin{array}{l}\text { Finance and } \\
\text { economics }\end{array}$ & $\begin{array}{l}\text { - Calculate internal rate of return } \\
\text { and other financial metrics } \\
\text { - Evaluate opportunity cost }\end{array}$ & $\begin{array}{l}\text { - Facilitate make-buy analysis } \\
\text { - Evaluate all tax issues }\end{array}$ & $\begin{array}{l}\text { - Update economic return } \\
\text { - Manage cash flow }\end{array}$ \\
\hline
\end{tabular}

Figure 1: A multidisciplinary hierarchical framework for product design (Figure reproduced from Cheng et al. 2009 and Seider et al. 2017 with permission from Elsevier).

product-process design. Grossmann (2004) introduced product-process design as one of the future challenges of chemical engineering. Hill (2009) proposed chemical product design as a third paradigm in chemical engineering. Smith and Ierapepritou (2010) discussed the integration of product design strategies in their review paper. MacDowell et al. (2010) discussed $\mathrm{CO}_{2}$ capture solvent and process design in their paper. $\mathrm{Ng}$ et al. (2015) reviewed significant development, current challenges, and future opportunities in the field of chemical product design using CAMD tools. Gani and Ng (2015) reviewed product design focusing on product conceptualization. Zhang et al. (2016) reviewed methods for chemical product and process design and discussed the challenges and opportunities and the perspectives for the future of product-process design. Fung et al. (2016) proposed a grand model for chemical product design, which consists of a process model, a property model, a quality model, a cost model, a pricing model, an economic model, as well as factors such as company strategy, government policies, and regulations. There are a lot of outstanding textbooks on product design (Wei 2007, Cussler and Moggridge 2011) and books of product design case studies (Ng et al. 2006, Brockel et al. 2013). With the multidisciplinary nature of product design, a summary of the key achievements across different disciplines of product design is noteworthy. This review article is organized in terms of research advances for the design tasks classified in Figure 1. These design tasks are grouped as five topics in this review paper, namely project management, market study, product design, process design, and economic analysis.

\section{Project management}

In the current competitive market, the time to market is critical for a product to succeed, and effective project management is crucial to make sure that all the milestones for developing a product are completed as scheduled. The diverse nature of the design tasks to be completed by a multidisciplinary team in product development makes project management even more challenging. Traditionally, project management process includes five elements, namely initiation, planning, production or execution, monitoring and controlling, and closing, as Figure 2 shows (Westland 2007). All projects start with an idea for a product. The initiating 


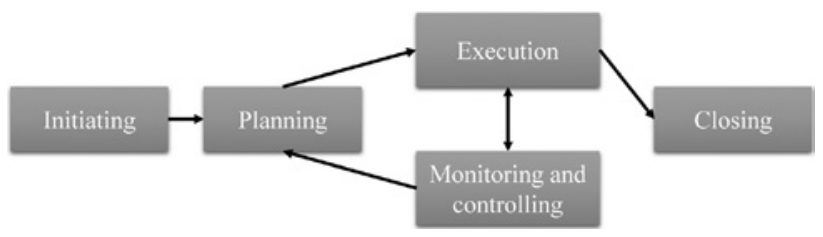

Figure 2: Project management stages.

process group then determines the nature and scope of the project. After initiation, the project is planned to an appropriate level of detail. The main goal is to reserve the adequate time and resources to complete the work needed and to manage risk effectively during project execution. The work defined in the planning process is then performed to achieve the project's objectives. The execution process involves coordinating people and resources, as well as integrating and performing the project activities. The deliverables are produced as outputs from the tasks performed, as defined in the project management plan. The monitoring and controlling group involves managing and tracking the project. Potential problems can be identified quickly for the team to take corrective action. It ends once the project has achieved its goals and objectives. Closing a project means finishing all activities of product design, and the designed product is ready to be brought to market.

Various methods have been developed to manage the progress of product development and to decide if a design project should be continued or not.

\subsection{Objective-time chart}

The objective-time chart, a concept very similar to Gantt chart, has been developed to manage the objectives and subobjectives that have to be met within a given time horizon (Ng 2004, Cheng et al. 2009). Figure 3 shows a generic objective-time chart, where objective $\mathrm{C}$ is decomposed into subobjectives $\mathrm{C}-1-\mathrm{C}-5$, and subobjective $\mathrm{C}-3$ is decomposed into C-3-1-C-3-4. The product-process design team uses objectivetime charts to assign tasks to their team members and the time by which they should be completed. Every member also knows what other members are doing to achieve the overall goal together. The objective-time chart also highlights the tasks that can be carried out concurrently, thereby reducing the overall development time (Cheng et al. 2009).

\subsection{The Stage-Gate product innovation process}

In addition to monitoring the progress of product development, decisions have to be made timely if a project

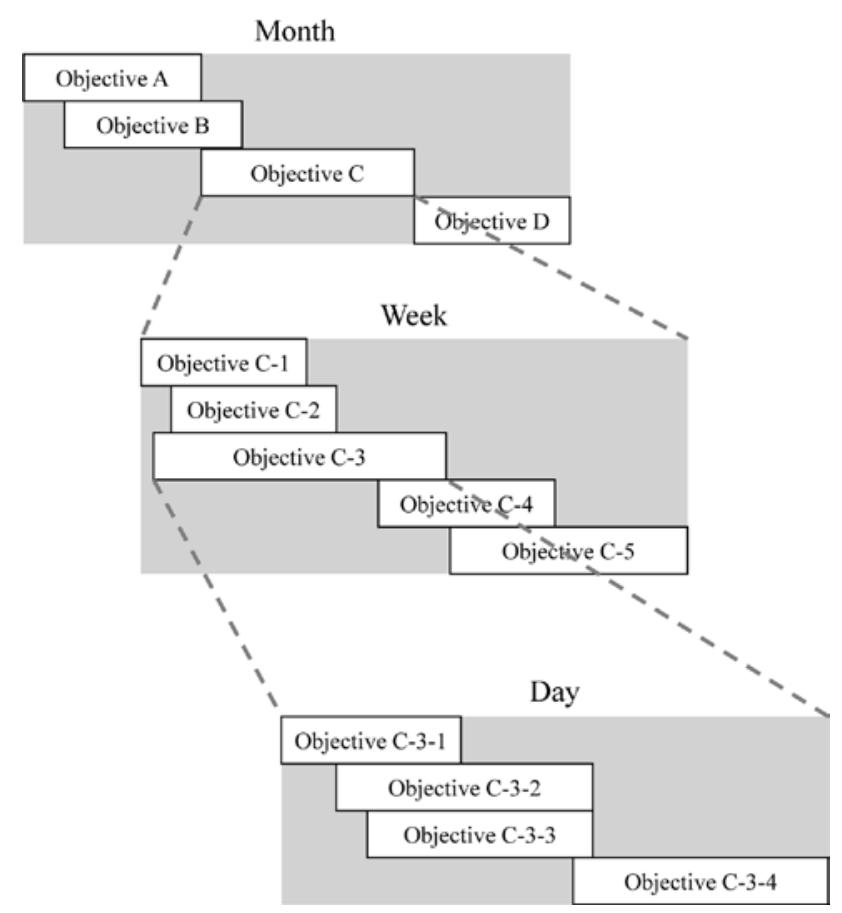

Figure 3: Objective-time chart (Figure reproduced from Cheng et al. 2009 with permission from Elsevier).

should continue or not. Cooper (1999) developed StageGate, which divides the product development process into five stages - product ideas generation, feasibility test for each product idea, process development for each feasible product idea, process optimization and scale up, and plant construction for product manufacture and marketing plan for product launch. At each stage, there is a gate review meeting to consider if the project can be advanced to the next stage or not. It also makes decisions on whether a project should be cancelled for reasons such as the product that cannot make any profit due to competition from others, or the need is no longer recognized by the company, among others.

\subsection{Balanced scorecard methodology}

There are many other methods developed for project management. For example, Mozota (2006) suggested the use of balanced scorecard (BSC) methodology to consider four aspects of product design, namely customer perspective, process perspective, learning perspective, and finance perspective. The customer and finance perspectives are easier to understand as the terms imply that product design is customer-oriented and aims at getting a larger profit and market share, respectively. The process perspective facilitates the product design and manufacturing process. One 
option is to adopt modular approach, in which a product is built up of smaller subunits that can be designed independently yet function together as a whole (Baldwin and Clark 1997). An example is Hsu and Liu (2010); they adopted BSC structure and aimed at automobile industries to understand the relationships of internal and external, financial and nonfinancial, and outcome and driving factors. They further probed and understood the feasibility of environmental performance evaluation and environmental strategy control. The learning perspective in BSC methodology refers to a continual process to improve the products so as to cope with the market change.

\section{4 $\operatorname{RAT}^{2} 10$}

To effectively manage product development, different resources are needed to complete all the tasks in product design. An RAT ${ }^{2} I O$ mnemonic acronym that stands for resources, activities, time, tools, input/output information, and objective summarizes what is needed for product development. Thus, we identify in advance the resources (people and money) required to complete certain activities (experiments, modeling, and synthesis) within a specified period of time using proper tools (experimental setup or software) to generate the necessary information and to meet the given objective. There are usually a wide range of information and knowledge required for product design.

\subsection{Knowledge management system}

A knowledge management system that creates, organizes, retrieves, and effectively exploits the knowledge of a specific domain is important to allow relevant information be obtained timely to facilitate the design and decision making process such that the company can stay competitive in the market. For example, Sun et al. (2010) developed a generic ontology-based approach knowledge management system for product design. The product knowledge model is the key of the system as it stores various information related to product design, including the required domain knowledge of the product under design, the business process that manipulates all the knowledge assets, and the company organization that identifies personnel with a particular skill for performing specific tasks. Using the knowledge management system, engineers can identify the most related technical and personnel information for their design tasks. Lee et al. (2014) developed a knowledge-based platform for formulating chemical products in the personal care industry. The subjective product design requirements (e.g. product texture, regulation compliance) provided by the marketing department are converted into objective product attributes (e.g. viscosity, smoothness) so that the formulation of a previously developed product that possesses product attributes closely matched with the desired ones can be retrieved from the system, and they are used as the base case for modification in the new product design (case-based reasoning). This greatly improves the communication between the marketing team and the technical team and minimizes the iteration required in developing a product so that new products can be launched to the market more efficiently. Similar knowledge-based system for product formulation has been developed for oil- and fat-based products (Avramenko and Kraslawski 2006) and pharmaceutical tablets (Craw et al. 1998).

\subsection{Agile project management}

The agile project management approach originated from software development and has also been adopted for product design project management. Agile management is an iterative, incremental method of managing the design and build activities of engineering, information technology, and other business areas that aim to provide new product or service development in a highly flexible and interactive manner. As Figure 4A shows, in a traditional waterfall product development approach, project managers identify a number of steps to accomplish a project, which typically must be completed sequentially and depending on type of project could include: requirements, design, implementation, and completion. The agile product development approach is rooted in principles of "human interaction" management. As Figure 4B shows, different from the waterfall method's preplanned process, in an agile product development approach, the

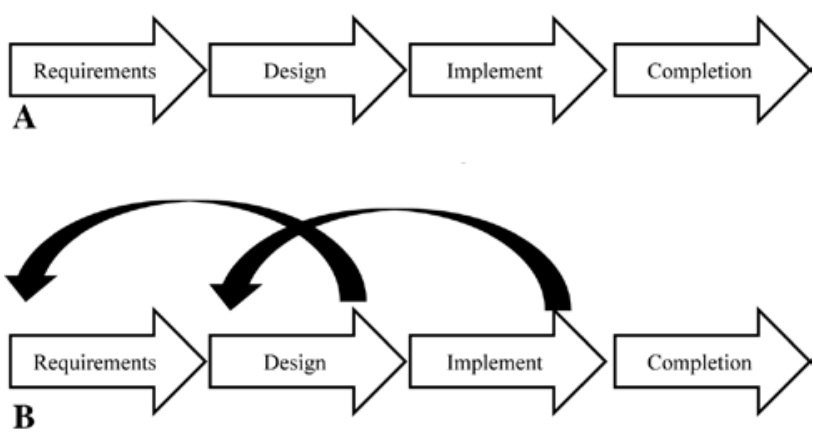

Figure 4: Comparison of $(A)$ waterfall and (B) agile approach in product management. 
project manager defines the project as a series of small tasks and completes them in a responsive and adaptive manner. This approach does not require the impractical assumption of "knowing all requirements." Besides, agile methods are people oriented rather than process oriented. Communication and motivation are essential, project managers and clients or other workers must be in communication daily and provide updates to one another to receive new information. Therefore, the key issue of applying agile methods to product design project management is to interactively refine the design process with communication and motivation with people to achieve reliability and flexibility. Molhanec (2008) improved the product design project management by using the agile project management method. The proposed agile project management method includes four phases: initiate, construct, deliver, maintain, and support. A set of information and communication technology and knowledge management methods/tools are included in the project framework for supporting the whole project process. Their approach is based on usage of Unified Modelling Language (a general-purpose, developmental, modeling language that is intended to provide a standard way to visualize the design of a system) standard diagrams for process description.

\subsection{Challenges}

On average, large projects overrun budget and time, while delivering less value than predicted. The project management is conducted under uncertainty and risk, especially during the initiation phase of the project. Therefore, the project has to be managed taking into account the uncertainty and risks that they are likely to face. The challenge here is how to plan for the risks so as to achieve the goal with minimal disruption. This could be achieved through the four-stage process of risk management (Pinto 2007), which includes risk identification, analysis of probability and consequences, risk mitigation strategies, and control and documentation. Risk identification is the process of determining the specific risk factors that can reasonably be expected to affect your project. A useful method for developing a risk identification strategy begins by creating a classification scheme for likely risks, such as financial risk, technical risk, etc. Then, a number of methods, both qualitative and quantitative, are available for conducting risk factor identification for industry-specific risks, including brainstorming meetings, expert opinion, history, and multiple (or team-based) assessments. In analysis of probability and consequences stage, the potential impact of these risk factors is determined by how likely they are to occur and the effect they would have on the project if they do occur. Here, a risk impact matrix reflects all identified project risks is constructed. In risk mitigation strategies stage, there are four possible alternatives a project organization can adopt in deciding how to address risks (Pinto 2007): (1) accept risk, (2) minimize risk, (3) share risk, or (4) transfer risk. In the control and documentation stage, a knowledge base for future projects based on lessons learned is created to help managers classify and codify the various risks the firm faces, its responses to these risks, and the outcome of its response strategies. Another challenge of project management is that there may exist no project mandate and unclear expectations. For many product design projects, there are no clear mission and objectives for the product design. Therefore, it is difficult for an at-risk project to recover. The stakeholders could also change their requirements and expectations rapidly. Therefore, agile methods have to be considered for any project and need to be integrated into the management methods to overcome the challenges and respond to the changes rapidly. A four-step strategy for agile project management has been proposed by Molhanec (2008) for a product design project: initial phase, construct phase, deliver phase, and support phase. Alongside these four project phases, there are activities running through the whole product life cycle as well. These are quality assurance $(\mathrm{QA})$, risk management, training and education, information and communication technology, reuse and knowledge management, metrics management, deliverables management, and infrastructure management.

\section{Market study}

All products have to fulfill customer requirements to stay competitive in the market. Therefore, market study is necessary because it gathers information about target markets and consumers. Market study helps to identify new business opportunities and supports the successful transformation of new technological knowledge into new products. It is an important component of business strategy. Market study provides important information to identify and analyze the market needs, market size, and competition. It plays a role in determining the need for most of the new products. However, caution should be taken in terms of the expectations of market research, for it cannot be assumed that conducting research with the market will uncover sizeable opportunities and lead to the conception and launch of new products. It is the role and responsibility of the researcher to use the understanding 
of the needs of the market to find applications for new products that will satisfy these needs. Furthermore, the market study cannot be assumed as an exact science, as it would be unrealistic and unreasonable to expect market researchers to predict the precise demand for a new concept, given that there are numerous variables that can impact demand outside of the market researchers' remit. Market study should be regarded as an experiment that includes social and opinion research using statistical and analytical methods and techniques of applied social sciences to gain insight or support decision making. The market study techniques encompass both qualitative techniques such as focus groups, in-depth interviews, ethnography, as well as quantitative techniques such as customer surveys and conjoint analysis (CA), quality function deployment (QFD), and lead user (LU) (Von Hippel 1986). Various methodologies have been developed for market study to identify the required consumer preferences and how to translate these qualitative consumer preferences into quantitative technical parameters. The advantages of different market analysis methods are found in Table 1.

\subsection{Conjoint analysis}

CA is a marketing technique to obtain information on consumers' preferences for product attributes, which can be used for new product development (NPD), market share forecasting, market segmentation, and pricing decisions. The method confronts respondents with descriptions or pictorials of products and asks them to rank or rate them according to their preferences. It does not require data on actual purchase behavior. Consumer preferences for certain features of new products are evaluated long before the products are actually developed. This makes the technique especially rewarding in the context of concept testing for new products. CA was first applied to market research by Green and Rao (1971) to understand how buyers made complex purchase decision, to estimate preferences and importance for product features, and to predict buyer behavior. A product or service area is described in terms of a number of product attributes. Each attribute can then be broken down into a number of levels. The preference of the product can be treated as a function of these attributes and their levels. They explained that conjoint measurement is concerned with the joint effect of two or more independent variables (product attributes). Then, it can be determined what combination of a limited number of attributes is most influential on respondent choice or decision making. Then preference models or utility functions indicate the perceived value of the feature and how sensitive consumer preferences are established based on the collected information. Based on their work, Green and Srinivasan (1978) developed a linear programming (LINMAP) procedure for rank ordered data for the parameter estimation and establishing preference function of CA. Later in 1985, Johnson (2001) from Sawtooth Software released a software system called adaptive CA. The software could adapt the survey to each individual in real time, asking only the most relevant trade-offs in an abbreviated, more user-friendly way that encouraged more realistic responses. Louviere and Woodworth (1983) developed a choice-based approach, which is used to provide choices to the consumers in the survey, to CA and related techniques such as Best-Worst Scaling. For example, for traditional CA, the consumer needs to rate from 1 to 5 in the survey for each aspect, while in their approach, they only need to make choices from provided candidates. In their approach, the CA and discrete choice theory in econometrics are integrated for the design and analysis of controlled consumer choice or resource allocation experiments. They are concerned with estimating the parameters of preference functions from discrete choice or allocation data. There are drawbacks in these developed CA methods. First, the number of attributes in use is heavily restricted. In order to use more attributes, hybrid conjoint techniques were developed to

Table 1: Advantages of different market analysis methods.

\begin{tabular}{lcc}
\hline & Conjoint analysis & Quality function deployment \\
\hline Identification of new product ideas & & $\checkmark$ \\
Reduction of market uncertainty for new products & $\checkmark$ & $\checkmark$ \\
Reduction of resistance against new products inside the company & & $\checkmark$ \\
Increased validity of market forecasts & $\checkmark$ & $\checkmark$ \\
Better decision making with respect to the marketing mix & $\checkmark$ & $\checkmark$ \\
Reduction of development times and development cost & $\checkmark$ \\
Reduction of planning uncertainty, improved decision making & & $\checkmark$ \\
Reduction of interface problems & & $\checkmark$ \\
Increased product quality & & $\checkmark$ \\
\hline
\end{tabular}


overcome this drawback (Green 1984). Second, the task of establishing preference function using CA itself was unrealistic and did not link directly to behavioral theory. In real-life situations, the task would be some form of actual choice between alternatives rather than the more artificial ranking and rating originally used. Louviere et al. (2000) pioneered an approach that used only a choice task, which became the basis of choice-based CA and discrete choice analysis. This stated preference research was linked to econometric modeling and can be linked to reveal preferences where choice models are calibrated on the basis of real rather than survey data.

\subsection{Quality function deployment}

QFD is a process to help identify customer requirements, and to structure the design and development of a solution to meet those requirements. It enables users to collect and then systematically analyze and record information. The information relates to user needs and to the methods and plans for manufacture, implementation, distribution, delivery, etc. The QFD method was first reported in the late 1960s in Kobe shipyard in Japan. Akao (1972) and Nishimura (1972) were the pioneers who proposed the QFD approach and reported the applications of the new approach in industry in their papers. In the 1980s, it was introduced to the Xerox Corporation and was then started to be applied and gained interest in the post-TQM era of the 1990s (Hauser and Clausing 1988). It has now been used in a wide range of situations such as car components design, blast furnace performance improvement, hotel and leisure industry, and strategic planning activities. In a NPD project, the design requirements (WHAT's) serve as input to establish the component characteristics (HOW's) of the product design, which on their turn serve to define the process plans and next the manufacturing process operations. Because of the complex relationships between the inputs and outputs, these relationships are mapped into a QFD chart as Figure 5 shows. In the QFD chart, each "HOW" will be appraised to set target goals or values, the "HOW-MUCH's" we want to achieve. These "HOWMUCH's" should be measurable as much as possible. The QFD is often applied by building a "House of Quality" as it was named by Hauser and Clausing (1988). The steps are given in Figure 5 and explained in Govers (1996).

\subsection{Lead user}

The LU method is a market research tool, developed by Urban and Von Hippel (1988), that may be used by

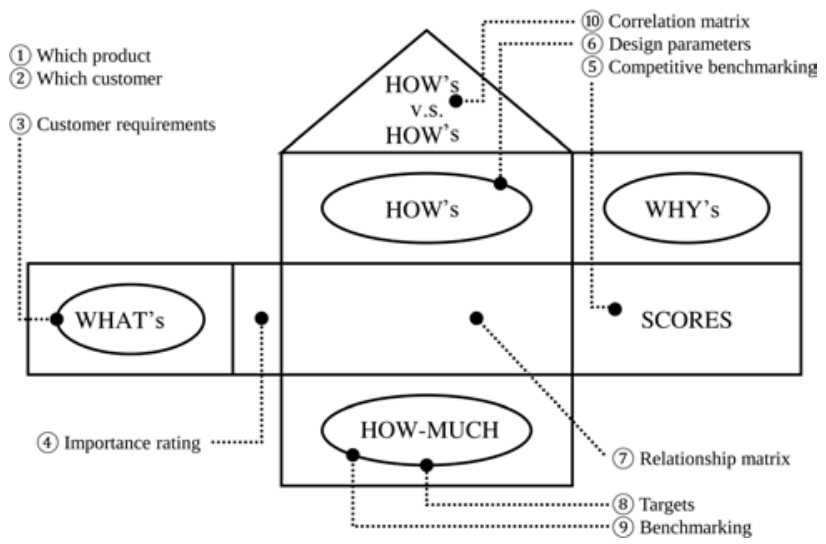

Figure 5: “House of Quality” and steps in the QFD process.

companies and/or individuals seeking to develop breakthrough products. Urban and Von Hippel (1988) pointed out that current market research analyses are typically not reliable in the instance of very novel products or in product categories characterized by rapid change, such as "high-technology" products. Therefore, in marketing research analyses of these products, the "LUs" of a product or process must be considered. LUs are users who are interested in more innovative products (leading edge) for a specific product category in the market. They present strong needs that will become general in a marketplace months or years in the future. The LU methodology involves four major steps (Von Hippel 1986):

1. Identify an important market or technical trend: Before one can identify LUs in a given product category of interest, one must identify the underlying trend. But general and reliable methods for formal prediction of trends over time on a given product area are not yet well developed. Only prediction methods for special case are developed and used currently.

2. Identify a group of LUs of the identified market or technical trend: The market researcher begins to search for LUs (1) who are at the leading edge of each identified trend in terms of related new product and process needs and (2) who expect to obtain a relatively high net benefit from solutions to those needs.

3. Analyze the data obtained from the needs of LUs: Data derived from LUs and their real-life experience with novel attributes and product concepts of commercial interest can be incorporated in market research analyses using standard market research methods such as CA and QFD.

4. Apply the LU data to the target market: The needs of today's LUs are typically not precisely the same as the needs of the users who will make up a major share of tomorrow's predicted market. Thus, analysts will 
need to assess how LU data apply to the more typical user in a target market rather than simply assume such data straightforwardly transferable. One approach involves prototyping the novel product and asking a sample of typical users to use it. However, in rapidly moving fields in which the proposed new product will interact with many other not-yet-developed in unforeseen ways, new approaches may be needed.

LU is an important information source for the development of new products with respect to three aspects: first, it provides insights in future market needs; second, it has often developed own innovations related to these new market needs from the interaction between the LUs by further analyzing their needs and can thus be regarded as an important source of innovative ideas; third, it provides the richest information to marketing researchers. The LU method is now utilized in any industry and at any level of product complexity. For example, LU concepts developed and used at $3 \mathrm{M}$ showed product sales potential that was an average of eight times higher than for sales of products using more traditional development concepts/processes (Lilien et al. 2002). Review articles of LU methods can be found in Lilien et al. (2002) and Lüthje and Herstatt (2004).

\subsection{Challenges}

There are challenges in the current market study. Careful selection of the questions asked in market analysis is of primary importance. First, it requires professional experiences to set up the models. Experienced market analysts are always needed in the market study as poorly designed studies may overvalue or undervalue some of the essential parameters in product design. Second, innovations that require potential users to try something new are difficult to research. Given that potential buyers or users interview without sufficient time to fully consider the product, it could have received the thumbs down. Third, people's taste change slowly. They gradually see and acknowledge the adoption of products by others, and over time, they are influenced by regular exposure to promotions. An initial rejection of a new product in a market research study may shortly become an enthusiastic embrace as attitudes change. Hence, market research cannot be expected to give definite and direct answers to new product. Therefore, new product research needs more intuition and judgment from the market researcher. Lee et al. (2014) have pointed out another challenge in market analysis. Sales teams analyze the market trends and define the desired product attributes before creating a NPD enquiry for the formulators in the R\&D department. However, some product attributes are defined by the sales and marketing department, such as the smoothness and softness of products, which are sensorial and thus subjective. Sales staff lack the technical knowledge to help them precisely express their preferences regarding those attributes. As a result, miscommunication between sales staff and formulators can easily occur as their perceptions of these subjective product attributes are different. From their research, a knowledge-based ingredient formulation system (KIFS) allows sales personnel, who lack technical skills, to input new product requirements based on their marketing analysis in linguistic terms when describing product properties. This narrows the gap between marketing and R\&D as the marketing information is inputted into the KIFS and transformed into technical knowledge for supporting the NPD activities.

\section{Product design}

Product design is the most important aspect, as it determines the performance of the product directly. Chemical products can be classified in terms of molecular products, formulated products, functional products, and devices (Gani and Ng 2015). Molecular products are products with single species such as solvents and refrigerants. Molecular products are usually part of a mixture-formulated product, employed as the main active ingredient of chemical-based products, or manipulated to obtain a specific product function. Formulated products are obtained by mixing selected components together to get the desired product attributes. Thus, a sunscreen lotion may consist of zinc oxide particles and other ingredients such as emollients. An inkjet ink is a mixture of key ingredients, such as pigments or metal nanoparticles, and supporting ingredients, such as dispersants and solvents. A liquid shampoo is a mixture of surfactants, fragrances, and colorants. Paints have pigments and a solvent, normally water, which evaporates to give a solid coat of paint. Functional products are those chemical products made up of materials that perform a desired function. Generally, these products do not have feed and outlet streams and do not involve mechanical and electrical parts. For example, a controlled-release herbicide granule can control weed growth over a prolonged period of time. A similar example is a moisture absorber using silica gel to lower the humidity in an enclosed environment such as a 
coat cabinet. For packaged foods, metalized polyethylene can be used to prevent the penetration of oxygen. Chemical devices are those chemical products that perform a particular purpose, especially those with mechanical and electrical parts. Often, a feed stream to a chemical device is transformed into an outlet stream with characteristics specified in the product attributes by performing reactions, fluid flow, heating/cooling, and/or separations. For example, an indoor air purifier transforms an air stream laden with volatile organic compounds (VOCs) into clean air by catalytically decomposing the VOCs with platinum-doped $\mathrm{TiO}_{2}$ under UV irradiation. A home-use reverse osmosis (RO) module rids tap water of liquidborne contaminants by forcing water molecules through an RO membrane (Seider et al. 2017). Figure 6 shows the design workflow diagram and relationship between the design of molecular products, formulated products, functional products, and devices. As can be seen, molecular design can be used to generate novel molecules that are not available in the existing database but offer properties needed in the formulated products, and the design of functional products and devices need formulated products design models.

These chemical products can also be classified as technology-push products and demand-pull products based on the design methods. For technology-push products driven by the discovery of a new functional ingredient, the active ingredient is already fixed. The focus is on specifying the appropriate supporting ingredients such that the product processes additional product attributes desired by potential consumers. For demandpull products, the R\&D activities begin with finding the suitable active ingredient(s). The relevant chemistry knowledge provides a good starting point to identify potential candidates (Seider et al. 2017). For all of these product design projects, it is important to discuss whether or not to begin the design project before the new technologies are in place. Therefore, it is helpful to create an innovation map, which connects the new materials or processing technologies to market needs (Widagdo 2006). It has four basic layers: new materials and/or processing technologies, technical-value proposition, products, and customer-value proposition. The innovation map is not just the reverse of QFD. It is related to a technology platform, expressed in the form of experience, knowhow, structure, and so on that enables the creation of products and processes without having to resort to a new technology (Seider et al. 2017). Technology platforms (e.g. polymer melt processing) require understanding of scientific fundamentals and manufacturing operations (e.g. multilayer thin films involving polymer rheology, and compacting and extrusion devices). Other examples include colloidal structures, surfactants, and emulsifiers for blending to form stable creams and pastes,

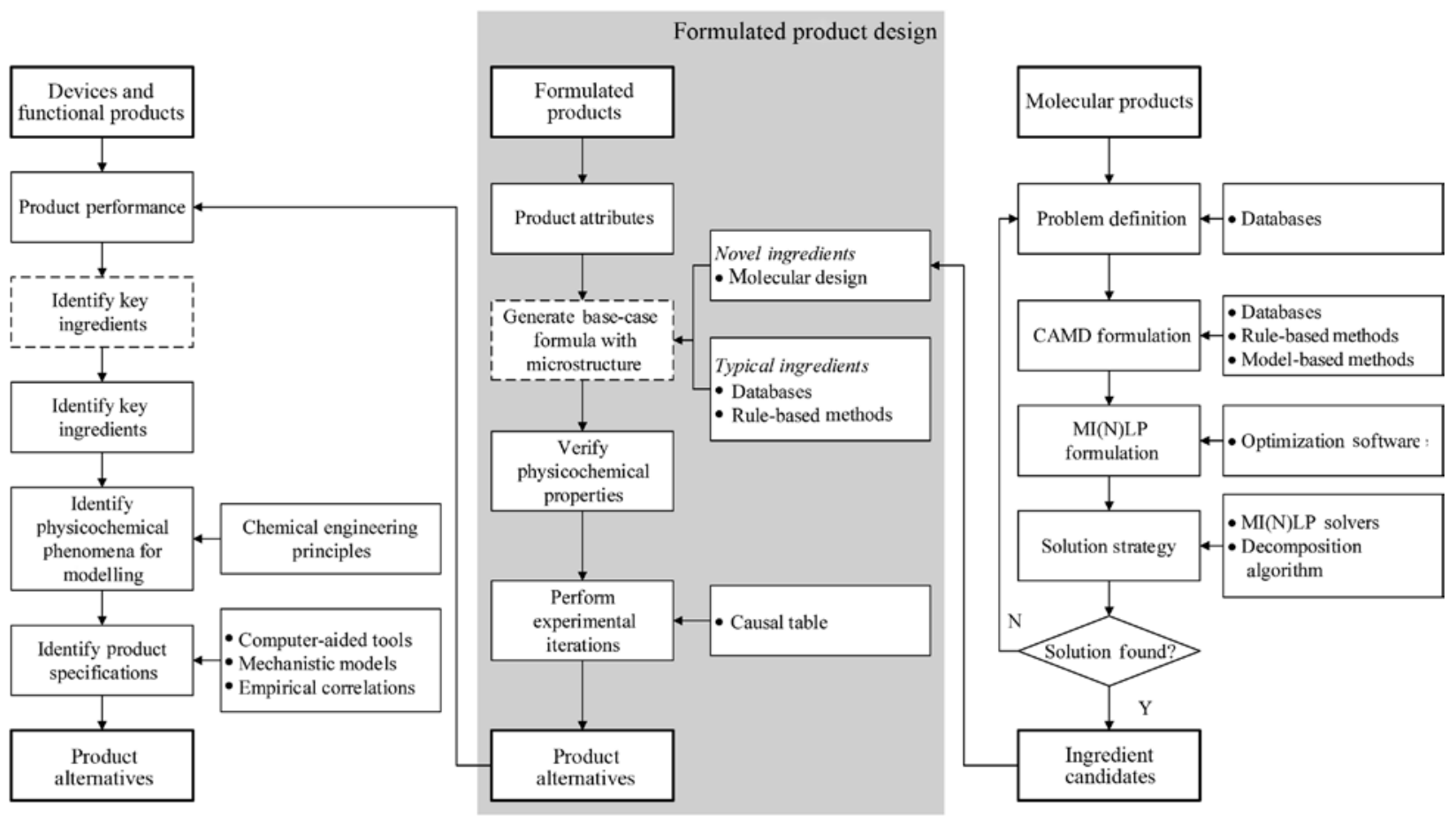

Figure 6: The workflow diagram for the design of molecular products, formulated products, and functional products and devices. 
human metabolism to build tissues to regenerate bone structures, and diffusive strategies of chemical (or drug) delivery from within nanoparticles. In some cases, large chemical companies, like 3M, have developed the science and processing techniques to accompany a large number of technology platforms. For each technology platform, teaching materials have been developed for employee training and development.

An IP patent search to check that no existing products are competitive with the new product being developed is also important. These are important sources of which the design team must be aware to avoid the duplication of designs protected by patents. Perhaps more significantly, patent searches are often indispensable in tracing the development of new technologies when creating innovation maps (Seider et al. 2017). Patents from the United States, Great Britain, Germany, Japan, and other countries are available on the Internet. Some other resources including SciFinder are also available to search for helpful patents in designing products and processes. It can be used to search by text, chemical structure, or chemical reactions.

For different types of products, the design approaches are also different. Researchers have developed various methods and tools to systematically generate product alternatives to meet market and engineering requirements and to quantitatively analyze those alternatives so as to select the best alternatives. These methods can be classified into experiments, database search, heuristics, and model-based approaches. Table 2 illustrates some examples of product design cases with their design methodology. Table 3 summarizes the advantages and disadvantages of different product design approaches. It should be noted that the product design methods are often integrated for a product design project. It is usually not possible to design a product by one single design method, especially for complex products.

\subsection{Experimental approach}

Many product design problems, especially big molecules, formulated, functional products, or chemical devices, are developed through trial-and-error experiments by specialists with extensive experience in producing the type of products under consideration. Experiments are necessary in such kind of product design problems because when data are missing and property model or other related models are not completely understood, it is not possible to use a model-based approach for the design problem. The missing data or models have to be obtained from experiments. For example, in an inkjet ink formulation (Cummins and Desmulliez 2012), formulation specialist would have most of the key ingredients, typical solvents and dispersants in the laboratory. For a new application, it is just a matter of mixing the several selected ingredients to form a mixture and adjusting its composition to obtain the desired properties. This approach, however, is not possible for engineers with limited experience in formulating such a product. Thus, it is too expensive and takes too long to experimentally screen a large number of product prototypes. Experiments can help to generate models for future product design. For example, in formulating conductive inks (Tam et al. 2016), they used experiments to generate the specific surface energy model of PET substrate for the selection of dispersing medium (for example tetradecane, ether, toluene, and cyclohexane). But for some other scenarios where no models can be developed, experiments are the only way to come up with reasonable products. For example, most of the design of organic coatings (Wicks et al. 2007) is through experiments since the lack of predictive property models especially for the property of color. Gani and Ng (2015) proposed an integrated experimentmodeling procedure that can help alleviate the problems for this kind of product design problems. In this procedure, CAMD is used to generate a list of potential product candidates, afterward, experimental testing measures and

Table 2: Examples of product design problems.

\begin{tabular}{lll}
\hline Product design problem & Product type & Methodology \\
\hline $\begin{array}{l}\text { Refrigerants design (Duvedi and Achenie 1996) } \\
\text { Solvent design (Klein et al. 1992) }\end{array}$ & $\begin{array}{l}\text { Molecular products } \\
\text { Molecular products }\end{array}$ & $\begin{array}{l}\text { Computer-aided molecular design } \\
\text { Computer-aided molecular design }\end{array}$ \\
$\begin{array}{l}\text { Perfume (Teixeira et al. 2012) } \\
\text { Sunscreen lotion (Conte et al. 2012) }\end{array}$ & $\begin{array}{l}\text { Formulated product } \\
\text { Formulated product }\end{array}$ & $\begin{array}{l}\text { Predictive model combined with experimental methodologies } \\
\text { Computer-aided tools integrated with experimental testing }\end{array}$ \\
$\begin{array}{l}\text { Drug release from erodible tablets } \\
\text { Katzhendler et al. 1997) }\end{array}$ & Functional product & $\begin{array}{l}\text { Mathematical model with regression model from } \\
\text { experimental data }\end{array}$ \\
$\begin{array}{l}\text { Die attach adhesive (Miragliotta et al. 2001) } \\
\text { Indoor air purifier (Seider et al. 2017) }\end{array}$ & Functional product & $\begin{array}{l}\text { Experiments } \\
\text { Inhalers for drug delivery (Wang et al. 2012) }\end{array}$ \\
\hline
\end{tabular}


Table 3: Advantages and disadvantages of different product design approaches.

\begin{tabular}{|c|c|c|c|}
\hline & Examples & Advantages & Disadvantages \\
\hline Experiments & $\begin{array}{l}\text { - Trial and error (Cummins } \\
\text { and Desmulliez 2012) } \\
\text { - Design of experiments (Roy } \\
\text { 2001) }\end{array}$ & $\begin{array}{l}\text { - Can be applied without any } \\
\text { theory and knowledge } \\
\text { - Often lead to safe and } \\
\text { reliable product }\end{array}$ & $\begin{array}{l}\text { - Limited test opportunities (a better product may } \\
\text { have been missed) } \\
\text { - Time consumption } \\
\text { - Waste materials }\end{array}$ \\
\hline Databases & $\begin{array}{l}\text { - NIST Chemistry web book } \\
\text { (Linstrom and Mallard 2001) } \\
\text { - ICAS database (Gani 2002) }\end{array}$ & $\begin{array}{l}\text { - The properties are reliable } \\
\text { - Fast candidates' generation }\end{array}$ & $\begin{array}{l}\text { - Not all molecules are listed in any database } \\
\text { - There could be no property data available in the } \\
\text { database }\end{array}$ \\
\hline Heuristics & $\begin{array}{l}\text { - Inkjet ink design by Tam } \\
\text { et al. (2016) } \\
\text { - Cream and paste design by } \\
\text { Wibowo and } \mathrm{Ng}(2001)\end{array}$ & $\begin{array}{l}\text { - Often lead to safe and } \\
\text { reliable product } \\
\text { - Provide quick and relatively } \\
\text { inexpensive solution } \\
\text { - Easy to apply when one } \\
\text { knows the rules }\end{array}$ & $\begin{array}{l}\text { - A better product may have been missed } \\
\text { - Experience, insight, and available knowledge are } \\
\text { needed. } \\
\text { - The rules are sometimes contradictory. } \\
\text { - Only valid within a narrow product context }\end{array}$ \\
\hline $\begin{array}{l}\text { Model-based } \\
\text { approach }\end{array}$ & $\begin{array}{l}\text { - CAMD (Harper and Gani } \\
\text { 2000) } \\
\text { - Molecular dynamics } \\
\text { (Sharma et al. 2016) }\end{array}$ & $\begin{array}{l}\text { - Global optimal solution can } \\
\text { be achieved } \\
\text { - No need to have in-depth } \\
\text { knowledge once the model } \\
\text { is ready } \\
\text { - Can be applied to all kinds } \\
\text { of product design problems }\end{array}$ & $\begin{array}{l}\text { - The size and complexity of the mathematical } \\
\text { programming model (especially for complex } \\
\text { products) } \\
\text { - A lot of physicochemical phenomena occurring are } \\
\text { not completely understood (no model available) } \\
\text { - Lack of relevant property models for some products } \\
\text { - The error of the property model }\end{array}$ \\
\hline
\end{tabular}

evaluates the needed properties of the products. Although heuristics and experimental approach often leads to the development of a safe and reliable product and a corresponding production process, it is not practically feasible to evaluate all alternatives with this approach. That is, a better product may have been missed (Zhang et al. 2016).

\subsection{Database search}

Database search is the fastest and least expensive method. Many electronic databases have a "search" capability, and this permits a search from a set of properties constraints to obtain a list of feasible substances. For the currently available databases, the search capability is available only for some of the most common physical parameters, such as boiling points, and densities, but not available for the less common parameters such as toxicity and global warming potential. The database search method is usually applied for some simple molecular product design and ingredients selection of complex products such as formulated products, functional products, and devices. It is an important tool for the design of these kinds of products to provide candidates for further selection.

\subsection{Heuristics approach}

Chemical products have been traditionally designed and developed through heuristics and experimental approaches. Heuristic-based approaches are more relevant for structured products. The most well-known heuristic-based approach is the hierarchical decomposition method developed by Douglas (1988) in process design, demonstrating that this technique could provide an acceptable framework for structured product design problems. In the early stages of design, when data are generally lacking, heuristics are needed to systematically generate and analyze alternatives (Hill 2009). Others have begun to identify heuristics related to design various engineering parameters of a chemical product. Fung and $\mathrm{Ng}$ (2003) proposed rules to select chemicals for granular products such as tablets and capsules in the form of a database search and then test them through a combination of models and experiments. Wibowo and Ng (2001) presented similar rules for chemical selection and a systematic procedure for the synthesis of manufacturing processes for creams and pastes. Hill (2004) proposed a heuristic rule for skin cream manufacture that involves heating/cooling, premixing, mixing, melting/crystallizing, emulsification, to create a desired droplet distribution. Wibowo and Ng (2002) proposed a systematic framework for product-centered processing for developing chemical-based consumer product manufacturing process, which provides directions and guidelines toward the development of a process for manufacturing a product with the desired performance in reduced time and effort. Lau et al. (2012) developed an integrative approach for the design and process development of nanoemulsion and 
nanodispersible solids. In their approach, formulation, stability testing, and performance testing of nanomized products are considered. Wang et al. (2012) designed an inhaler for drug delivery using heuristics with parameters determined experimentally. Inhalable dry powder form of drug-loaded lipid-polymer hybrid nanoparticles was successfully produced in the form of microscale aggregates of the nanoparticles. Seider et al. (2017) designed an indoor air purifier using four-step heuristic rules for chemical devices with parameters determined experimentally, simplified model using only the key mechanisms is used. In heuristic method, the design problem is solved indirectly, by generating alternatives and testing them for feasibility; that is, the number of alternatives is systematically reduced through heuristics. A set of rules is derived from a combination of experience, insight, and available knowledge. The major difficulty with the heuristic method is that the rules are sometimes contradictory and difficult to apply; they are valid within a narrow product context and a comprehensive methodology for incorporating heuristics across a broader product domain has yet to be established. The advantage is that these methods are easy to apply. When the search space is not very large, the best solution can be determined.

\subsection{Model-based product design approach}

Recent work has established how to mathematically represent the generic product-engineering problem (Gani 2004). In this approach, the product design problems are formulated as an MILP/mixed-integer nonlinear programming (MINLP) optimization model, in which molecular structure, product property prediction model using group contribution method, and process model equations are the constraints. From the solution of the optimization model, the optimal product is obtained. This approach is mainly focused on single molecular products and some formulated and functional products in the current status. The design problem for these kinds of products is solved using model-based methods and/or computer-aided tools (numerical solver or algorithm). Model-based product design approaches are widely applied now on computeraided molecular/mixture design. Other applications of model-based approaches are establishing models to reveal and simplify the relationships of the design variables, such as ingredient composition, product microstructure, product preference, etc. For example, Tam et al. (2016) established correlations and models based on transport phenomena, material databases, and experiments in the design of conductive inks. From the established equations, the relationships between the product preference and the ingredients' properties, composition, and product use conditions are established to help design the optimal conductive ink. Lau et al. (2013) have reported the processing steps needed to manufacture herbal medicines. The QA procedure was based on a model that accounts for the physicochemical phenomena governing herbal extraction. With their model and the companion experiments for determining the relevant model parameters, the amount of each herb needed from different herb quality classes to produce a Chinese herbal medicine decoction with consistent quality can be determined. Model-based methods are also used widely in functional products and devices. For example, rate equation for the catalytic oxidation of air purifier (Seider et al. 2017), dissolution rate for tablets (Katzhendler et al. 1997), etc. Although modelbased methods are promising and widely used today, there are limitations for the application of the methods to all products. A major difficulty for this design approach is the size and complexity of the mathematical programming model. The scope and significance of the problems solved depends on the availability and application range of the models used, especially the property models.

For simpler molecular products and mixtures, researchers have developed algorithms and tools for computer-aided product design. Gani and Brignole (1983) proposed a rule-based synthesis-design method, called "generate and test." In their method, algorithms are developed to generate all the possible molecules from combining the groups, then properties are estimated using group contribution method for each generated molecule. The molecules within the range defined by the property constraints are kept as candidates. The generate and test method was extended by Klein et al. (1992) to design a formulated product - solvent mixtures. Harper and Gani (2000) proposed a multistep and multilevel approach of the "generate and test" method for chemical product design which includes problem formulation step incorporating a knowledge base for the identification and setup of the design criteria; candidate compounds generation step using a multilevel generate and test CAMD solution algorithm with a high level of molecular detail, a postsolution step for result analysis and verification. Many mathematical programming methods are also available for molecular design. Venkatasubramanian et al. (1994) applied genetic algorithms to solve molecular and pharmaceutical product design problems. Later, the application of mathematical programming with group contribution method for property estimation methodology was expanded to polymer design (Vaidyanathan and El-Halwagi 1994). Sahinidis et al. (2003) also used an MINLP model for a refrigerant 
design problem. Papadopoulos and Linke (2006) proposed the integration of solvent selection and process design problem, with the environmental impact taken into account. Conte et al. (2011) developed a systematic modelbased computer-aided methodology for design and verification of liquid formulated products. Their methodology was part of an integrated three-stage approach: generate a list of feasible product candidates using computer-aided tools, planning of experiments, and experimental testing and design modification. Cignitti et al. (2015) presented a framework for computer-aided design of pure and mixed chemical based products. In their framework, the product needs and target properties are systematically converted into a MINLP problem and sequentially solved through a decomposed optimization approach. Zhang et al. (2015) proposed a generic MILP/MINLP mathematical programming formulation, with the consideration of higher-order groups for molecular structure representation and property estimation.

For product design problems, there are two big hurdles preventing the large-scale use of model-based approach (Hill 2004). First, most physicochemical phenomena occurring, especially for structured products and devices, are not completely understood. This makes rigorous modeling difficult. Second, there is a lack of relevant property models for structured products.

\subsection{Challenges}

Although various methods and tools have been developed, a major issue of the product design problems is the range of applications of the developed solution approaches. The difficulty here is the availability of data knowledge and models that can extend the application regions of the currently available methods and tools. The multidisciplinary nature and the multiscale representation of the problem must be considered for the modeling of the product design problem. This will greatly increase the size and nonlinearity of the problem, and the solution approaches for efficiently solving complex problems are also a great challenge. The challenges for small molecular products are to find the suitable alternative molecule that can lead to significant reduction in energy costs, environmental impact, and waste. For large molecular products, the additional incentive to determine an easier synthesis route is very attractive, as it can make a potential candidate molecule economically feasible. The challenges for formulated products and functional products are to extend the search space in which new molecules can be considered. For formulated and functional products, the salient chemical features of the product define its performance during application. These features are product specifications that include the key ingredient and additives, their composition, and the product structure. For single phasestable liquid ones, only the properties and composition of the ingredients determine the performance. The challenge is to find a product formula that performs better than the presently available ones at reduced cost. Another challenge here is that mixing rules are needed; they are derived from physicochemical theory or from experimental results. For structured products, the product structure will also have a huge influence on the performance, and the product structure is commonly determined from the process. Therefore, the involved phenomena-microstructure-property-process relations must be understood sufficiently so that the necessary mathematical models that do not currently exist can be developed. The challenges of devices are to find better alternatives of the chemicals and materials to those currently in use. Another challenge here is the difficulty to describe the exact phenomena relevant to the performance or manufacture of the chemical device. Often, assumptions and simplifications are needed to develop model-based methods to describe the transport phenomena and to find the optimal sequence of processing steps. This requires experience to develop a reasonable and reliable model. However, model-based methods are not always feasible to obtain the desirable information, for example, touch and feel, aroma, color, and esthetics. In this case, it is better to perform experiments and use a black box model to relate the input parameters to the outcome. In many cases of device design, the physical phenomena are so complex that the experimental testing is the method of choice (Gani and Ng 2015). In device design, various design methods including experiments, heuristics, model-based approaches as well as case-based knowledge system are needed. Therefore, developing a general framework integrating all these approaches for optimal design of device will remain a challenge.

\section{Process design}

Chemical process design establishes a practical means to convert raw materials to products with desired properties and functionality via a series of processing steps. Chemical product design and process design are intimately related. Producing a desired chemical product requires a feasible process, and no process will be implemented for a chemical species that is not desired. For best results, both the product and the process should be optimal. The chemical 
product and process design problems and their integration, along with product applications, are illustrated in Figure 7 (Zhang et al. 2016). Note that the product from a designed process must match the properties (needs) of the designed product, and the performance of the product during application must match the functions of the product. The specifications of a product of known structure, composition, and properties that needs to be produced are normally considered as the starting point of process design. The application aspect of a chemical product, highlighted in Figure 7, is not normally included in product and/or process design, even though the sustainability of the product depends on it. The simultaneous product-process design problems have also been studied by many researchers. Despite all recent developments, the number of products and their processes that can be designed with model-based techniques is still very small. Mainly heuristics combined with data are applied for product-process design of structured products, even though the ability to solve large complex problems has improved. Traditional processing techniques such as crystallization and extraction have been studied for a long time, and various models are developed that can be used to formulate a product-process design problem. The processing techniques used in many products are unconventional processing techniques such as coating, sintering, nanomization, and so on. They do not have well-developed models. Therefore, the limitation for the product-process design is still a lack of data and theory on which needed property and process models can be developed and employed (Zhang et al. 2016). Before the start of a process design project, it is also necessary to develop an innovation map and technology platforms and do an IP patent search. Here, the technology platforms are important as the process operations to create "unconventional" chemical products need to be improved. Consequently, strategies for process synthesis, including heuristic approaches and mathematical programming, need to account for new processing technologies associated with each technology platform.

\subsection{Unconventional processing technique}

Many techniques in current product production are not conventional technique like distillation, adsorption, etc., but unconventional ones like coating, granulation, etc. Here, we call these new processing techniques "unconventional processing techniques." To identify these relevant unit operations, the truly essential principles, and/ or yet-to-be-categorized features, the typical products and their manufacturing processes should be known in some detail (Ng et al. 2006). Thus, the challenge is to collect all of this product and process information, which, ideally, should come from experienced practitioners in the various industrial sectors. These unconventional processing techniques can be summarized as Figure 8 shows. The current unconventional processing techniques can be classified into two groups: addition/formation and removal/destruction. In the addition/formation group, there are three main techniques: coating, agglomeration, and synthesis. Coating is a covering that is applied to the surface of an object. The purpose of applying the coating may be decorative, functional, or both. Deposition of solid, liquid and vapor precursors can be used for coating. Agglomeration is a size enlargement process used in the chemical process industries to impart better functionality to a product, thus avoiding common processing problems and providing the consumer with a better product experience. Lamination,

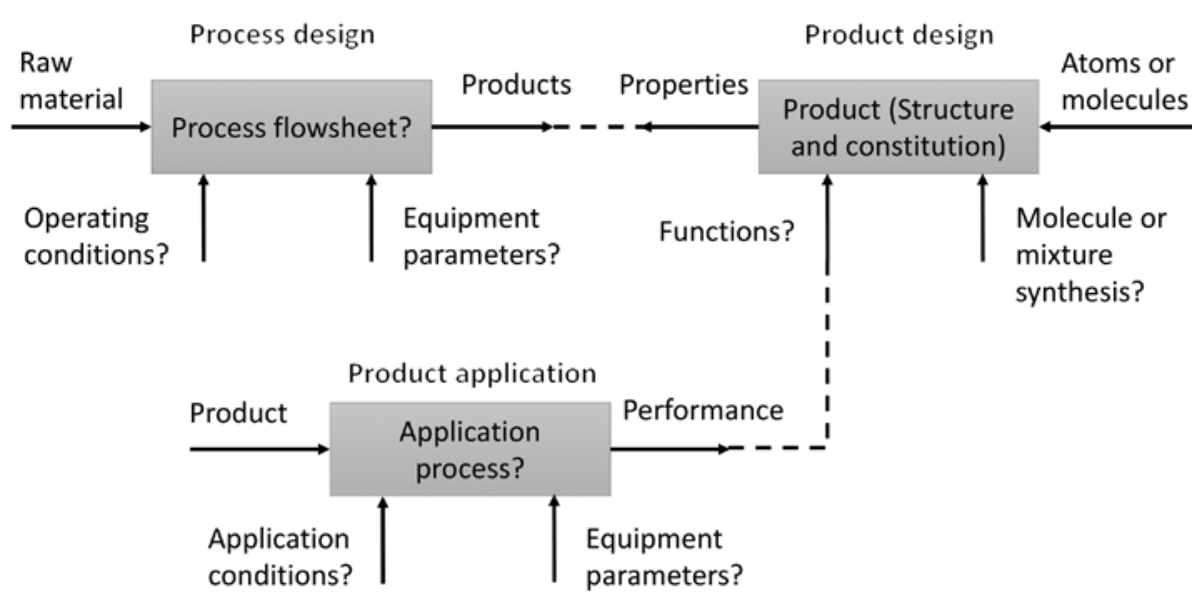

Figure 7: Relationship between process design, product design, and product application (Figure reproduced from Zhang et al. 2016). 


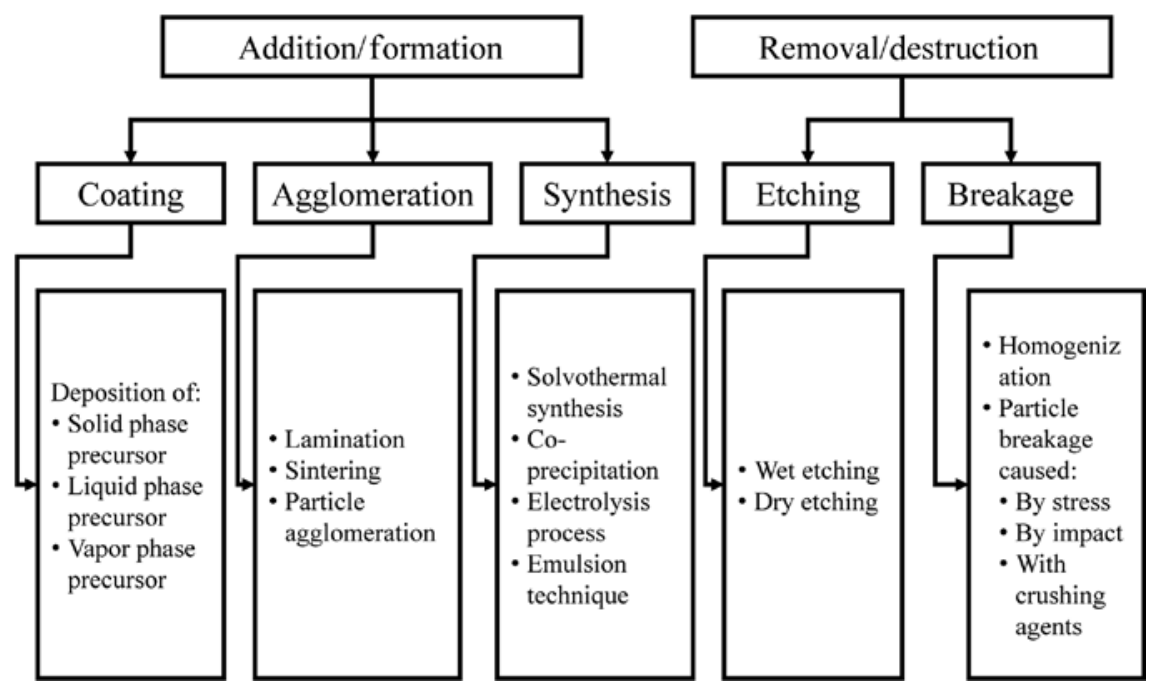

Figure 8: Unconventional unit operations.

sintering, and particle agglomeration are commonly used techniques for agglomeration. Solvothermal synthesis, coprecipitation, electrolysis process, and emulsion techniques are commonly used for synthesis. In the removal/ destruction group, there are two main techniques: etching and breakage. Etching is the process of chemically removing layers from the surface. It typically occurs within the process of photolithography. Wet etching techniques use aqueous solution of acids or alkalis to react with a portion of the thin films and forms a soluble salt, which can be dissolved and washed away. Dry etching removes a portion of the film by ion removal or by chemical reaction between the activated gas in a plasma and the film. Breakage and coalescence are two competing phenomena in emulsion formation. Particle breakage is caused by stress (Jaw crusher), impact (Hammer mill), and crushing agents (Ball milling). Babi et al. (2015) pointed out that novel, sustainable, and innovative solutions may not be found by working at the unit-operation scale. Babi et al. (2015) and Lutze et al. (2013) proposed the synthesis design of processes from the phenomena scale, just as atoms and functional groups are used to synthesize and design single-species chemical products. This phenomena-based synthesis could also be a possible direction for understanding the unconventional processing techniques. The development of generic models for describing these unconventional processing techniques is still a long way to go.

\subsection{Heuristic approach}

Many unconventional processing technologies are used in producing structured products. The models for these processing technologies are not fully developed. Therefore, model-based methods are not commonly used for these structured products, and heuristic approaches are more often used here. Batch processes are a popular method for manufacturing formulated and functional products, especially for those in low volume or processes that require several complicated steps in the synthesis procedure (Harding and Floudas 1997). Douglas (1988) proposed a multilevel hierarchical procedure for the synthesis and design of batch and continuous chemical processes. This hierarchical decomposition idea, together with rules to reduce the alternatives, has also been applied by Barnicki and Fair (1990) for the separation process synthesis and by Jaksland et al. (1995) for a more comprehensive method for synthesis and design of chemical processes. Siirola (1996) proposed another type of hierarchical decomposition based on the meansends analysis for synthesis of chemical processes. $\mathrm{Ng}$ (2001) presented a strategy for the synthesis of chemical manufacturing processes, issues, methods, and tools for the approach were illustrated with processes involving crystallization and solids processing steps. Martins et al. (2007) added sustainability issues to the Douglas method. Many hierarchical approaches have already been developed for product-process design. Wibowo and Ng (2001) presented a systematic procedure for the synthesis of manufacturing processes for creams and pastes. In their procedure, the desired functional and sensorial performance of the product is first identified in terms of quality factors, then the requisite ingredients are selected, and the process flowsheet, as well as the operating conditions, is synthesized by heuristics and compared to determine the best flowsheet by process simulation. Wibowo 
and $\mathrm{Ng}$ (2002) proposed a systematic framework for product-centered processing for developing chemicalbased consumer product manufacturing process. A fivestep procedure was developed in their framework: define the product functionality, form, and packaging; identify the relevant quality factors; select necessary ingredients and determine product microstructure; design the manufacturing process in light of the desired product properties; and evaluate by process simulation to select the optimal process. Hill (2004) discussed the heuristic methods for structured products such as soap bars and skin cream. Fung et al. (2006) presented a systematic iterative procedure in integrating analyses with experiments for determining granulator operating parameters to produce granules with desired product attributes, including granule size, size distribution, porosity, strength, and spatial distribution of the constituent components. Fung et al. (2007) proposed a product-centered process development procedure for detergent products. The procedure adopted a new integrative product-centered approach that calls for close cooperation between the marketing personnel. Cheng et al. (2010) developed an integrated approach for a transdermal patch containing a traditional Chinese medicinal tincture. In their approach, the tasks of market study, product design, prototyping, and process design were considered. The disadvantages here are each of the developed heuristic approach can be applied only in a certain range of products, and the solution obtained cannot be guaranteed as optimal.

\subsection{Mathematical programming}

Researchers have also started studying integrated product-process design problems using mathematical programming. Hostrup et al. (1999) reported the integration of solvent selection-design with design of separation processes involving azeotropes. They formulated an MINLP problem and solved it in the decomposition way. Eden et al. (2004) presented a new product-process design model that couples the product design problem and process design problem and solves them simultaneously. This allows more integration between the two problems because the same molecular groups for product design are now variables used to describe process properties. Karunanithi et al. (2005) proposed a systematic decomposition of MINLP problem without model reduction where the design of solvents, together with crystallization process, was integrated. Papadopoulos and Linke (2006) proposed the integration of CAMD and process synthesis design problem, taking into account environmental impact.
In mathematical programming approaches for process design, first a superstructure is created that has embedded a large number of alternative designs. Then mathematical techniques such as MINLP are used to find the optimum process within the specified superstructure. Thus, process synthesis problems can also be formulated as superstructure optimization problems and integrated into product design problems. The current research in product-process design is focused only on some simple molecular products and formulated products. It is difficult to implement product design and process design using mathematical programming approach simultaneously for more complex products because the product design methods for this kind of product are not mature and the process models have not been fully developed. The disadvantages here are that the processes have to be fully understood and the process models have to be fully developed, and only those processing routes included in the superstructure can be investigated.

\subsection{Challenges}

Chemical engineers can contribute substantially to product design alongside the physical chemists, materials scientists, and food technologists, in addition to their unique role in process design. However, there are many challenges in the research of process design. Questions still not resolved are how to incorporate all possible processing techniques in the processing routes. Although heuristics may be helpful for the generation of possible processes, they are not comprehensive and may at times conflict (Hill 2004). Hence, heuristics require a framework if they are to be more useful for process synthesis. One popular comprehensive heuristic framework for chemical process synthesis is the hierarchical decomposition methodology developed by Douglas (1988). Mathematical programming is another primary approach for process design. For mathematical programming techniques to be employed, models representing all alternatives are needed, adding the complexity of the availability-uncertainty of the model parameters. Hill (2004) also pointed out that mathematical programming could be expanded to cover processes for the manufacture of more complex products such as structured products, and perhaps even simultaneous product and process design. However, significant hurdle impedes the application of mathematical programming to these problems. Complete scientific elucidation of the underlying chemical and physical phenomena behind many products and their processes is still lacking, and the relevant data that could be used 
to further that scientific understanding are maintained as carefully guarded secrets within industry. This limited understanding makes rigorous modeling difficult. Therefore, the currently available methods and tools need further development and improvement. In addition, the processing techniques used in many products are very similar, and unconventional processing techniques are often used. The models for these unconventional processes are often not available and therefore need to be developed and employed for the simultaneous design of product and its process. Another challenge for process design is the integration of sustainability and life cycle assessment (LCA) issues. The incorporation of sustainability (including economic, environmental, and safety) indicators are important with respect to product-process integration. In the Grand Product Design model proposed by Fung et al. (2016), these issues are integrated. Also, the question of supply chain and availability of resources to convert raw material to the desired products needs to be considered for process design. Otherwise, many products are designed, but if they cannot be sustainably produced (manufactured), they do not become actual marketable products.

\section{Economic analysis}

Economic analysis is an evaluation of whether the product/project is profitable. It is needed in product design problems for evaluating the financial performance for the company of the product being designed. Any financial metrics such as net present value (NPV), internal rate of return (IRR), and return on investment (ROI) can be used in the economic analysis. From economic analysis, key parameters in economic such as price and demand can be determined. Various methodologies, such as experimental, mathematical, and comparative statics, have been developed for economic analysis. The experimental methods (Kagel et al. 1995) are concerned with applying economic data to test the validity of statements related to future economic developments. For example, if companies expect an increase in the demand for a certain product, economists would take data about the current and future condition of this particular production and would apply it to the current interest the public has toward this product. Thus, they can estimate predicted prices and demand for the product. Mathematical methods (Chiang 1984) use mathematics in calculating economic variables. The method embraces a huge variety of mathematical equations that aim to determine the current and future state of an economy. Comparative statics (Athey 1998) method is the economic method that compares two economic outcomes before and after a change in the economy. It is particularly useful when determining the demand and supply rates, when analyzing the whole economy, or when estimating impacts of monetary policies. For example, while using comparative statics, an individual can observe the change in the computer industry. Using data before the tablet innovations and after tablets appeared on the markets for the first time in 2009, it is logical to conclude that their demand in the future would increase because of the increasing public interest and rising amounts of tablet sales. Here, we focus the discussion on mathematical methods for maximizing the profit of a company with market behavior considered, so as to establish a comprehensive mathematical model for chemical product design.

\subsection{Economic metrics for product development}

There are two distinct periods for a product development project: a relatively short period of product development form idea to production and a long product life cycle consisting of introduction, growth, maturity, and decline phases. In the early stage of the product development period, information is often inaccurate and incomplete. Approximate profitability measures such as ROI and payback period can be used to obtain a rough idea of whether the project is a worthwhile effort. As more accurate information becomes available, project profitability should be evaluated using NPV or IRR. The NPV is given by

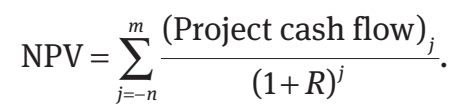

In Eq. (1), $R$ is discount rate and $n$ and $m$ are the number of periods of product development and product life cycle, respectively. The product development period is represented by $j<0$, where the project cash flow tends to be negative. Investment is needed to develop the new product but there is no income. The product life cycle is represented by $j \geq 0$, in which the project cash flow is supposedly positive. In the IRR approach, the discount rate is treated as an unknown in Eq. (1) and is calculated by setting NPV to zero. The discount rate thus calculated is referred to as the investor's rate of return, which should be as large as possible. It represents the interest rate for the investment made by the company. The investor's rate of return can be compared with the bank interest rate. If 
IRR is higher than the prevailing bank interest rate, we are ahead; otherwise, it is a bad investment project.

\subsection{Microeconomics of product development}

Profits have to come from sales revenue, which is the amount of product sold, multiplied by the unit price. The selling price of the new product is a function of product demand. Price elasticity of demand (PED) is a measurement used in economics to show the responsiveness of the quantity of product demand to a change in its price. Revenue is maximized when price is set so that the PED is exactly 1 . The PED of a product can also be used to predict the incidence of a tax on that product. Therefore, it is easy to appreciate that the sales volume or equivalently demand $\left(d_{n}\right)$ and selling price $\left(p_{n}\right)$ of the new product are two key decisions in product development. These two parameters $\left(d_{n}\right.$ and $\left.p_{n}\right)$ are closely coupled and are dependent on the consumer preference of the company's product $\left(H_{n}\right)$ and that of the competitor's $\left(H_{c}\right)\left(H_{n}\right.$ and $H_{c}$ are related to the product properties of our company's product and the competitor's product, respectively) the competitor's selling price $\left(p_{c}\right)$ and the total market size $(Y)$. An expression that relates all of these parameters is available (Bagajewicz 2007); it provides insights for business decision making.

$$
p_{n} d_{n}^{1-\rho}=\alpha^{\rho}\left(\frac{H_{n}}{H_{c}}\right)^{\rho}\left(\frac{Y-p_{n} d_{n}}{p_{c}}\right)^{1-\rho}
$$

and

$$
Y \geq p_{n} d_{n}+p_{c} d_{c}
$$

The left-hand side of Eq. (2) shows the fact that demand is expected to be inversely proportional to the price of the new product. Here, $\rho$ is an adjustable parameter related to product elasticity. $\alpha$ is a parameter with a value between 0 and 1 . It measures how much the consumer knows about the new product. Even if the quality of the company's product is better than that of the competitor's, it does not necessarily mean that the consumers recognize the value proposition and are willing to pay for it. If $\alpha$ equals 0 , the demand for the new product is zero as well, irrespective of the product price. The value of $\alpha$ can be raised by increasing the marking budget. The righthand side of Eq. (2) shows that a decrease in the price of the competing product has an increase in the price and demand of the new product. Eq. (3) expresses the fact that the consumer doesn't have to spend the total budget on the new and competing products. Cheng et al. (2016) proposed an approach for the economic analysis of chemical product design based on Bagajewicz's (2007) work. It took into account customers' preference on product quality and economic considerations such as pricing, profit, market share, capital investment, and operating cost. There are also other models developed to express the relationship between product price and demand; for example, Garcia-Herreros et al. (2016) used bilevel optimization model to find the product price and demand under competition behavior. In their method, from the modeling of competition behavior, the price-demand relationship is obtained through the solution of the bilevel optimization model. There are also other models proposed. Mahajan et al. (1982) proposed a conjoint model for measuring selfand cross-price/demand relationships. They described an approach to characterize each brand as a separate pricerelated factor in which respondents are asked to indicate their subjective likelihood of buying a set of brands. A first-order Markovian model is postulated to represent price-induced brand switching. Keskin and Zeevi (2014) presented a dynamic pricing with an unknown demand model. They consider a monopolist who sells a set of products, and the seller initially does not know the parameters of the products' linear demand curve but can estimate them based on demand observations.

\subsection{Sensitivity analysis}

There is a lot of uncertainty in marketing a product. The projected sales volume may turn out to be overly optimistic or the impact of advertisement on sales exaggerated. Therefore, it is often necessary to carry out a large number of what-if analyses to find out the possible impact of these uncertain parameters or scenarios on financial return. The aim of such an exercise is to form a mental picture of all possible outcomes of a product development project so as to minimize the number of surprises and to decide on the best course of actions. For example, an upper bound and a lower bound of the projected sales volume can be considered in an economic evaluation. Similarly, if there is uncertainty about the fixed cost, it can be changed to quantify the effect on financial return. In fact, completely different scenarios can be used in an economic evaluation to give the product development team a good sense of the potential impact.

\subsection{Challenges}

The stand-alone principle is normally assumed for calculating the potential financial return so that the product 
development project is evaluated on its own merits. In practice, many other factors that blur this clear view come into play. For example, it is not unusual to spend more research and development effort than what is needed for the intended product during the product development period. This is done to pave the way for the development of follow-up or related products. Also, due to the vast difference of processing techniques for product, the estimation of capital cost and operating cost of production and research equipment for the new product may not be very clear, especially on unconventional processing techniques. This adds the challenge in doing a reliable financial calculation. Also, governments and societies at large have their own goals and needs. Many start-up firms and large corporations take advantage of the financial incentives offered by the government. Such public money can significantly affect the financial return of a product development project. This should be accounted in financial calculations and the impact of government policies on product design should be studied.

\section{Perspectives}

Gani and Ng (2015) have pointed out the challenges of chemical product design in their paper. The first challenge for chemical product design is the multidisciplinary and diversity nature of chemical product design. Therefore, it is difficult to develop a clear view and general framework for product design problems. Researchers have developed various methods for molecular products and achieved good results. But for the design of formulated products and functional products and devices, property models and transport models for understanding their behavior are limited or not available; only experiments and heuristics are used for the design of a certain kind of products. Therefore, it is necessary to develop a general framework for chemical product design. In the general framework, different design methods should be included for different product design problems, such as experiments, heuristics, and computer-aided methods. Knowledge and casebased library is needed for similar design applications as references of the product design problems. In such a framework, the issues of sustainability, LCA, and supply chain should be integrated to design a sustainable, safe, environmental friendly, and marketable product. The uncertainties of data and model parameters also need to be addressed for robust and flexible product design. Researchers have attempted for the development of such kind of framework (Gani and Ng 2015, Fung et al. 2016) and case-based libraries (Lee et al. 2014), but more efforts are needed for the development of methods and tools for complex chemical products.

The second challenge is to reveal the relationship of the desired product attributes to the material properties of the ingredients, the structure of the product, and the processing steps. The product structure depends on the processing steps, and it has effects on the product attributes. Without the benefits of predictive models for these relationships, extensive trial and error by experiments is still required. Even if a comprehensive model based on first principles is not available, a combination of physical insights and heuristics can still help improve the development process. Consider the manufacture of granules for a controlled release formulation in a granulator. Because of the complex equipment design, interacting physicochemical phenomena, and the variety of materials involved in granulation, it is not possible to predict the operating conditions under which granules of the desirable particle size distribution, porosity, etc., can be produced. Combining models and experiments could be of help under these circumstances. This is despite the fact that much of the underlying physics has been elucidated in the past decade. Similar issues can be found in the manufacture of low-fat margarines, nanoparticles, aligned carbon nanotube devices, etc. Online process monitoring will find increasing applications in high-value product quality management, and they will need to be addressed in the early stages of product-process development.

The third challenge is the interface between engineering, business, and management. Traditionally, chemical engineers primarily participate in cost estimation for financial calculations in product design project. The consumer product sector demands closer ties to marketing and management, which play a key role in making the project a success. How far a chemist or chemical engineer should venture into these activities is unclear. However, armed with knowledge on the effects of materials and processing on product attributes, the chemical engineer is in a good position to contribute to product conceptualization and marketing. At many companies, such as 3M, four divisions are involved to address this issue: Technology Development, Business Development, Product Development, and Manufacturing. The challenge here is how to handle the risk and uncertainty of the market.

The fourth challenge is the difficulty in teaching product design. Although it has been taught for almost 20 years in various institutions, it has not spread broadly (Rodrigues and Cussler 2016). One of the reasons is the diversity of chemical products and the multidisciplinary nature of chemical product design. Therefore, it does not 
involve the same degree of definition as thermodynamics or fluid mechanics. Knowledge of physics, chemistry, chemical engineering, material science, industrial engineering, electronic engineering, marketing, and management is needed to appreciate and understand chemical product design in depth, something that a chemical engineering undergraduate may not possess until well into the senior year.

Although product design has been studied for several decades, and various methods have been proposed, there are still challenges and opportunities in chemical product design. As Zhang et al. (2016) pointed out, these challenges can be achieved by the combined effort from academia and industry to develop a systematic generic framework and tools including product simulator, process simulator, database manager, modeling tool, and templates for design problems.

\section{Conclusions}

In this review paper, we have provided an overview of chemical product design in the context of a multidisciplinary hierarchical framework. We considered the issues, methods, and challenges of related areas of chemical product design problems, including project management, market study, product design, process design, and economic analysis. Each product design project can be separated into these design tasks, and with a better understanding of the relationship between the design tasks and the methods and tools for these tasks, a design project can be better organized and executed to find optimal products.

\section{References}

Akao Y. New product development and quality assurance: system of QFD, standardization and quality control. Japan Stand Assoc 1972; 25: 9-14.

Athey S. Comparative statics under uncertainty: single crossing properties and log-supermodularity. MIT, Department of Economics, Working Paper No. 96-22. 1998. Available at: SSRN: https://ssrn.com/abstract=135528.

Avramenko Y, Kraslawski A. Similarity concept for case-based design in process engineering. Comput Chem Eng 2006; 30: 548-557.

Babi DK, Holtbruegge J, Lutze P, Górak A, Woodley JM, Gani R. Sustainable process synthesis-intensification. Comput Chem Eng 2015; 81: 218-244.

Bagajewicz MJ. On the role of microeconomics, planning, and finances in product design. AIChE J 2007; 53: 3155-3170.
Baldwin CY, Clark KB. Managing in an age of modularity. Harv Bus Rev 1997; 75: 84-93.

Barnicki SD, Fair JR. Separation system synthesis: a knowledge-based approach. 1. Liquid mixture separations. Ind Eng Chem Res 1990; 29: 421-432.

Brockel U, Meier W, Wagner G, editors. Product design and engineering: formulation of gels and pastes, Somerset, NJ: Wiley, 2013.

Cheng YS, Lam KW, Ng KM, Ko RK, Wibowo C. An integrative approach to product development - a skin-care cream. Comput Chem Eng 2009; 33: 1097-1113.

Cheng YS, Ng KM, Wibowo C. Product design: a transdermal patch containing a traditional Chinese medicinal tincture. Ind Eng Chem Res 2010; 49: 4904-4913.

Cheng YS, Fung KY, Ng KM, Wibowo C. Economic analysis in product design - a case study of a TCM dietary supplement. Chinese J Chem Eng 2016; 24: 202-214.

Chiang AC. Fundamental methods of mathematical economics. New York: McGraw-Hill, 1984.

Cignitti S, Zhang L, Gani R. Computer-aided framework for design of pure, mixed and blended products. Comput Aided Chem Eng 2015; 37: 2093-2098.

Conte E, Gani R, Ng KM. Design of formulated products: a systematic methodology. AIChE J 2011; 57: 2431-2449.

Conte E, Gani R, Cheng YS, Ng KM. Design of formulated products: experimental component. AIChE J 2012; 58: 173-189.

Cooper RG. Product leadership: creating and launching superior new products. Cambridge, MA: Perseus Books, 1999.

Craw S, Wiratunga N, Rowe R. Case-based design for tablet formulation. In: Smyth B, Cunningham P, editors. European Workshop on Advances in Case-Based Reasoning. Springer Berlin Heidelberg, 1998: 358-369.

Cummins G, Desmulliez MP. Inkjet printing of conductive materials: a review. Circuit World 2012; 38: 193-213.

Cussler EL, Moggridge GD. Chemical product design, 2nd ed., Cambridge: Cambridge University Press, 2011.

Douglas JM. Conceptual design of chemical processes, New York: McGraw-Hill, 1988.

Duvedi AP, Achenie LE. Designing environmentally safe refrigerants using mathematical programming. Chem Eng Sci 1996; 51: 3727-3739.

Eden MR, Jørgensen SB, Gani R, El-Halwagi MM. A novel framework for simultaneous separation process and product design. Chem Eng Process 2004; 43: 595-608.

Fung KY, Ng KM. Product-centered processing: pharmaceutical tablets and capsules. AIChE J 2003; 49: 1193-1215.

Fung KY, Ng KM, Nakajima S, Wibowo C. A systematic iterative procedure for determining granulator operating parameters. AIChE J 2006; 52: 3189-3202.

Fung HK, Wibowo C, Ng KM. Product-centered process synthesis and development: detergents. Comput Aided Chem Eng 2007; 23: 239-274.

Fung KY, Ng KM, Zhang L, Gani R. A grand model for chemical product design. Comput Chem Eng 2016; 91: 15-27.

Gani R. ICAS Documentation, PEC02-15. CAPEC Internal Report, Technical University of Denmark, 2002.

Gani R. Chemical product design: challenges and opportunities. Comput Chem Eng 2004; 28: 2441-2457.

Gani R, Brignole E. Molecular design of solvents for liquid extraction based on UNIFAC. Fluid Phase Equilibria 1983; 13: 331-340. 
Gani R, Ng KM. Product design - molecules, devices, functional products, and formulated products. Comput Chem Eng 2015; 81: 70-79.

Garcia-Herreros P, Zhang L, Misra P, Arslan E, Mehta S, Grossmann IE. Mixed-integer bilevel optimization for capacity planning with rational markets. Comput Chem Eng 2016; 86: 33-47.

Govers CP. What and how about quality function deployment (QFD). Int J Prod Econ 1996; 46: 575-585.

Green PE. Hybrid models for conjoint analysis: an expository review. J Marketing Res 1984; 21: 155-169.

Green PE, Rao VR. Conjoint measurement for quantifying judgmental data. J Marketing Res 1971; 8: 355-363.

Green PE, Srinivasan V. Conjoint analysis in consumer research: issues and outlook. J Consum Res 1978; 5: 103-123.

Grossmann IE. Challenges in the new millennium: product discovery and design, enterprise and supply chain optimization, global life cycle assessment. Comput Chem Eng 2004; 29: 29-39.

Harding ST, Floudas CA. Global optimization in multiproduct and multipurpose batch design under uncertainty. Ind Eng Chem Res 1997; 36: 1644-1664.

Harper PM, Gani R. A multi-step and multi-level approach for computer aided molecular design. Comput Chem Eng 2000; 24: 677-683.

Hauser JR, Clausing D. The house of quality. Harvard Bus Rev 1988; 63-73.

Hill M. Product and process design for structured products. AIChE J 2004; 50: 1656-1661.

Hill M. Chemical product engineering - the third paradigm. Comput Chem Eng 2009; 33: 947-953.

Hostrup M, Harper PM, Gani R. Design of environmentally benign processes: integration of solvent design and separation process synthesis. Comput Chem Eng 1999; 23: 1395-1414.

Hsu YL, Liu CC. Environmental performance evaluation and strategy management using balanced scorecard. Environ Monit Assess 2010; 170: 599-607.

Jaksland CA, Gani R, Lien KM. Separation process design and synthesis based on thermodynamic insights. Chem Eng Sci 1995; 50: 511-530.

Johnson RM. History of ACA. Proceedings of the Sawtooth Software Conference. Victoria, BC: Canada, 2001:205-212.

Kagel JH, Roth AE, Hey JD. The handbook of experimental economics, Princeton: Princeton University Press, 1995.

Karunanithi AT, Achenie LE, Gani R. A new decomposition-based computer-aided molecular/mixture design methodology for the design of optimal solvents and solvent mixtures. Ind Eng Chem Res 2005; 44: 4785-4797.

Katzhendler I, Hoffman A, Goldberger A, Friedman M. Modeling of drug release from erodible tablets. J Pharm Sci 1997; 86: 110-115.

Keskin NB, Zeevi A. Dynamic pricing with an unknown demand model: asymptotically optimal semi-myopic policies. Oper Res 2014; 62: 1142-1167.

Klein JA, Wu DT, Gani R. Computer aided mixture design with specified property constraints. Comput Chem Eng 1992; 16 : S229-S236.

Lau YT, Chen N, Ko KM, Ng KM. Product design: a nanomized nutraceutical with enhanced bioactivity and bioavailability. Ind Eng Chem Res 2012; 51: 7320-7326.

Lau YT, Ng KM, Lau DT, Wibowo C. Quality assurance of Chinese herbal medicines: procedure for single-herb extraction. AIChE J 2013; 59: 4241-4254.
Lee, CKH, Choy KL, Chan YN. A knowledge-based ingredient formulation system for chemical product development in the personal care industry. Comput Chem Eng 2014; 65: 40-53.

Lilien GL, Morrison PD, Searls K, Sonnack M, Hippel EV. Performance assessment of the lead user idea-generation process for new product development. Manage Sci 2002; 48: 1042-1059.

Linstrom PJ, Mallard WG. The NIST Chemistry WebBook: a chemical data resource on the Internet. J Chem Eng Data 2001; 46: 1059-1063.

Louviere JJ, Woodworth G. Design and analysis of simulated consumer choice or allocation experiments: an approach based on aggregate data. J Marketing Res 1983; 20: 350-367.

Louviere JJ, Hensher DA, Swait JD. Stated choice methods: analysis and applications, Cambridge University Press, 2000.

Lüthje C, Herstatt C. The Lead User method: an outline of empirical findings and issues for future research. R\&D Manage 2004; 34: 553-568.

Lutze P, Babi DK, Woodley JM, Gani R. Phenomena based methodology for process synthesis incorporating process intensification. Ind Eng Chem Res 2013; 52: 7127-7144.

MacDowell N, Florin N, Buchard A, Hallett J, Galindo A, Jackson G, Adjiman CS, Williams CK, Shah N, Fennell P. An overview of $\mathrm{CO}_{2}$ capture technologies. Energy Environ Sci 2010; 3: 1645-1669.

Mahajan V, Green PE, Goldberg SM. A conjoint model for measuring self- and cross-price/demand relationships. J Marketing Res 1982; 19: 334-342.

Martins AA, Mata TM, Costa CA, Sikdar SK. Framework for sustainability metrics. Ind Eng Chem Res 2007; 46: 2962-2973.

Miragliotta J, Benson RC, Phillips TE, Emerson JA. Simultaneous measurements of electrical resistivity and Raman scattering from conductive die attach adhesives. In: MRS Proceedings (Vol. 682, pp. N2-10). Cambridge University Press, 2001.

Molhanec M. Agile project management in product design. In 2008 31st International Spring Seminar on Electronics Technology (pp. 399-403). IEEE, 2008.

Mozota BB. The four powers of design: a value model in design management. Design Manage Rev 2006; 17: 44-53.

$\mathrm{Ng}$ KM. A multiscale-multifaceted approach to process synthesis and development. Comput Aided Chem Eng 2001; 9: 41-54.

Ng KM. MOPSD: a framework linking business decision-making to product and process design. Comput Chem Eng 2004; 29: 51-56.

Ng KM, Gani R, Dam-Johansen K. Product development - what to make and how to make. Comput Aided Chem Eng 2006; 23: 473-489.

Ng LY, Chong FK, Chemmangattuvalappil NG. Challenges and opportunities in computer-aided molecular design. Comput Chem Eng 2015; 81: 115-129.

Nishimura H. Ship design and quality table. Quality Control (JUSE) 1972; 23: 16-20.

Papadopoulos Al, Linke P. Multiobjective molecular design for integrated process - solvent systems synthesis. AIChE J 2006; 52: 1057-1070.

Pinto JK. Project management: achieving competitive advantage, Upper Saddle River, NJ, USA: Pearson/Prentice Hall, 2007.

Rodrigues A, Cussler EL. Teaching chemical product design. Educ Chem Eng 2016; 14: 43-48. 
Roy RK. Design of experiments using the Taguchi approach: 16 steps to product and process improvement, John Wiley \& Sons, 2001.

Sahinidis NV, Tawarmalani M, Yu M. Design of alternative refrigerants via global optimization. AIChE J 2003; 49: 1761-1775.

Seider WD, Lewin DR, Seader JD, Widagdo S, Gani R, Ng KM. Product and Process design principles: synthesis, analysis and design, 4th ed., Wiley, 2017.

Sharma A, Liu L, Parameswaran S, Grayson SM, Ashbaugh HS, Rick SW. Design of Amphiphilic Polymers via molecular dynamics simulations. J Phys Chem B 2016; 120: 10603-10610.

Siirola JJ. Strategic process synthesis: advances in the hierarchical approach. Comput Chem Eng 1996; 20: S1637-S1643.

Smith BV, lerapepritou MG. Integrative chemical product design strategies: reflecting industry trends and challenges. Comput Chem Eng 2010; 34: 857-865.

Sun W, Ma QY, Gao TY, Chen S. Knowledge-intensive support for product design with an ontology-based approach. Int J Adv Manuf Technol 2010; 48: 421-434.

Tam SK, Fung KY, Poon, GSH, Ng KM. Product design: metal nanoparticle-based conductive inkjet inks. AIChE J 2016; 62: 2740-2753.

Teixeira MA, Rodríguez 0, Rodrigues S, Martins I, Rodrigues AE. A case study of product engineering: performance of microencapsulated perfumes on textile applications. AIChE J 2012; 58: 1939-1950.

Urban GL, Von Hippel E. Lead user analyses for the development of new industrial products. Manage Sci 1988; 34: 569-582.

Vaidyanathan R, El-Halwagi M. Computer-aided design of high performance polymers. J Elastom Plast 1994; 26: 277-293.
Venkatasubramanian V, Chan K, Caruthers JM. Computer-aided molecular design using genetic algorithms. Comput Chem Eng 1994; 18: 833-844.

Von Hippel E. Lead users: a source of novel product concepts. Manage Sci 1986; 32: 791-806.

Wang Y, Kho K, Cheow WS, Hadinoto K. A comparison between spray drying and spray freeze drying for dry powder inhaler formulation of drug-loaded lipid-polymer hybrid nanoparticles. Int J Pharm 2012; 424: 98-106.

Wei J. Product engineering: molecular structure and properties, Oxford: Oxford Univ. Press, 2007.

Westland J. The project management life cycle: a complete step-by-step methodology for initiating, planning, executing $\&$ closing a project successfully, Kogan Page Publishers, 2007.

Wibowo C, Ng KM. Product-oriented process synthesis and development: creams and pastes. American Institute of Chemical Engineers. AIChE J 2001; 47: 2746.

Wibowo C, Ng KM. Product-centered processing: manufacture of chemical-based consumer products. American Institute of Chemical Engineers. AIChE J 2002; 48: 1212.

Wicks Jr ZW, Jones FN, Pappas SP, Wicks DA. Organic coatings: science and technology, John Wiley \& Sons, 2007.

Widagdo $\mathrm{S}$. Incandescent light bulb: product design and innovation. Ind Eng Chem Res 2006; 45: 8231-8233.

Zhang L, Cignitti S, Gani R. Generic mathematical programming formulation and solution for computer-aided molecular design. Comput Chem Eng 2015; 78: 79-84.

Zhang L, Babi DK, Gani R. New vistas in chemical product and process design. Ann Rev Chem Biom Eng 2016; 7: 557-582. 